\title{
Design and implementation of a broad-band high gain low noise amplifier for 3G/4G applications
}

\author{
Ahmed M. Abdelmonem', Ahmed S. I. Amar², Amir Almslmany ${ }^{3}$, Ibrahim L. Abdalla ${ }^{4}$, \\ Fathi A. Farag ${ }^{5}$ \\ ${ }^{1,4,5}$ Electronics and Communications Engineering, Zagazig University, Egypt \\ ${ }^{2}$ Electronics and Communications Engineering, Ain Shams University, Egypt \\ ${ }^{3}$ Electronics and Communications Engineering, Alexandria University, Egypt
}

\begin{tabular}{|c|c|}
\hline Article Info & ABSTRACT \\
\hline Article history: & The main aim of the paper is designing and implementing a broadband low- \\
\hline Received Mar 29, 2021 & $\begin{array}{l}\text { noise-amplifier (LNA) based on compensated matching network technique in } \\
\text { order to get high stable gain, low noise figure, low cost, and smaller size for }\end{array}$ \\
\hline Revised May 5, 2021 & $3 \mathrm{G} / 4 \mathrm{G}$ communication system applications at $2 \mathrm{GHz}$ with bandwidth 600 \\
\hline Accepted May 10, 2021 & $\begin{array}{l}\text { MHz. The advanced design system (ADS) simulates the proposed circuit. } \\
\text { The implementation was done with a class A bias circuit and a low noise }\end{array}$ \\
\hline Keywords: & $\begin{array}{l}\text { transistor BFU } 730 \mathrm{~F} \text { with a lower noise figure }\left(\mathrm{NF}_{\min }\right) 0.62 \mathrm{~dB} \text {. Collector } \\
\text { current is measured to be } 5.8 \mathrm{~mA} \text { and base current is } 19.1 \mu \mathrm{A} \text { with a supply }\end{array}$ \\
\hline $\begin{array}{l}3 \mathrm{G} / 4 \mathrm{G} \\
\text { Compensated matching } \\
\text { network }\end{array}$ & $\begin{array}{l}\text { voltage of } 2.25 \mathrm{~V} \text {. The new design proposed a }\left(\mathrm{NF}_{\min }\right) \text { of } 0.62 \mathrm{~dB} \text { with a } 17.8 \\
\mathrm{~dB} \text { high stable amplifier gain. The microstrip lines (MSL) and compensated } \\
\text { matching network techniques were used to improve the LNA's stability and } \\
\text { achieve a good result. The LNA board is implemented and assembled on the }\end{array}$ \\
\hline High stable gain & FR4 botton layer material. The results are virtually non existence equivalent \\
\hline Low cost & between the simulated and the measured results. \\
\hline
\end{tabular}

This is an open access article under the CC BY-SA license.

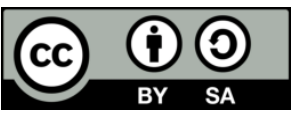

Corresponding Author:

Ahmed M. Abdelmonem

Electronics and Communications Engineering, Zagazig University

Zagazig Meetghamr Street, Zagazig, Egypt

Email: bakhom.ahmed@gmail.com

\section{INTRODUCTION}

The need for $3 \mathrm{G} / 4 \mathrm{G}$ portable wireless devices has prompted the invention of a low-noise-amplifier (LNA), as is well recognised. In a wireless system, the LNA is the first stage of most wireless receiver design. The effectiveness of the LNA block determines the RF receiver's efficiency. Cell phones are an excellent way to keep in touch with others and have become indispensable to many people all over the world. Today's technologically advanced cell phones (3G/4G) are capable of storing data, taking pictures, mobile internet access, video calls, mobile TV gaming services, and 3D television in addition to receiving and placing phone calls. In a multi-band mobile receiver, a broadband (BB) LNA is needed [1]. Briefly, the definition of the LNA is a reception system able to receive poor signals and enhancement it in order to satisfy the level acceptable for continuity the compared of device transceiver to the conventional narrow-band LNA. The wide-band LNA has a unique design that allows it to tackle a variety of challenges, including matching $\mathrm{BB}$ at the input to reduce reflection coefficient, adequate and gain, low (NF) and high linearity [2].

There are many techniques to design broadband LNA such as compensated matching network [3], balanced amplifier [4], distribution amplifier [5], and negative feedback [6]. Some references about this LNA designs have been published. The utilization of dual wide band with $(2-4 \mathrm{GHz}$ and $5-6 \mathrm{GHz})$ has been proposed in [7]. Also, $2.3 \mathrm{GHz}$ LNA for WiMAX is published in [8], at $2.3 \mathrm{GHz}$, the optimised LNA has a 
NF of $1.102 \mathrm{~dB}$ and gain of $15.11 \mathrm{~dB}$ [9]. At the interested band, the NF differs from 3-3.7 dB. This situation does not supportive the LNA designs for $3 \mathrm{G} / 4 \mathrm{G}$ applications. For this band, the designed LNA with a NF of $0.588 \mathrm{~dB}$, unconditional stable along and the gain of $12.85 \mathrm{~dB}$ has been published in [10].

In this paper, a broadband LNA based on compensated matching network technique has been designed and implemented at $2 \mathrm{GHz}$ in order to get high stable gain, low noise figure, and smaller size for a 3G/4G communication system. The manuscript is arranged as: The second section illustrates the LNA circuit design methods. The analysis, design steps and simulations by using ADS [11], which have been discussed in the third section. The implementation and simulation results have been introduced in the fourth section. Finally, the conclusions have been explained.

\section{BROAD BAND LNA CIRCUITS APPROACHES}

The key and challenge to realize broadband LNA design is to achieve high gain and ensure stability in the whole band. Figure 1 shows a simplified circuit diagram for the broadband LNA. The structures of the broad-band LNA are [12].

- Compensated matching network

- Balanced amplifier

- Distribution amplifier

- Negative feedback amplifier

The compensated matching network design is essential to obtain gain flatness results and low noise figure by using stepped impedance matching and a single short stub. The stepped impedance matching circuit (quarter-wave transmission line) helps the design to reduce the load and source reflection coefficient $(\Gamma)$ by making multiple steps $K / 4$ length of the transmission line (TL). So, the input impedance at the load or the source efficiency can be obtained as $\mathrm{Zin}=\mathrm{Z}_{0}^{2} / \mathrm{Z}_{\mathrm{L}}$; $\mathrm{Zin}=\mathrm{Z}_{0}^{2} / \mathrm{Z}_{\mathrm{S}}$ where $\mathrm{Z}_{\mathrm{o}}$ is the TL characteristic impedance. Also, a single short stub can be considered for matching circuit at source and load to improve the reflection coefficient.

A balanced amplifier is a cost-effective way to incorporate a broadband amplifier with flat gain and accurate input and output matching. The most common configuration is to use two (3-dB) hybrid couplers on a balanced amplifier. A distribution amplifier is a circuit that incorporates TL at the design in order to obtain a higher gain product than typical circuits can achieve.

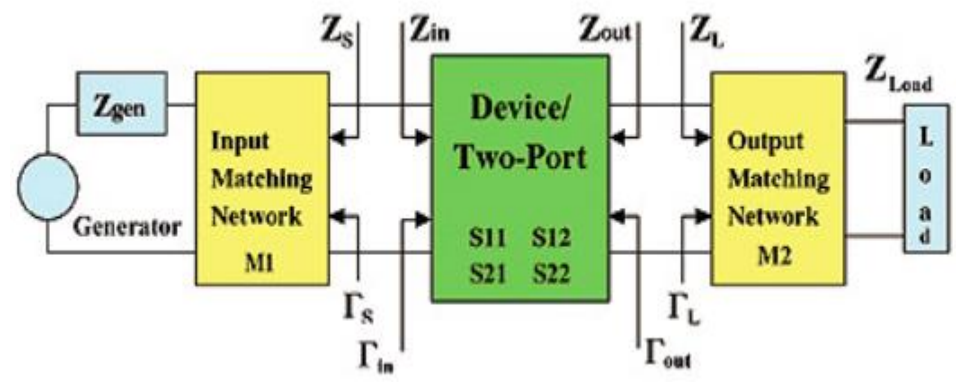

Figure 1. A simplified circuit diagram for the broadband LNA

In broadband amplifiers, negative feedback can be used to achieve a flat gain response at all the band and get lower NF. Additionally, it monitors the amplifier's output due to the differences in S-parameters between transistors. Negative feedback is classified into two types: shunt and sequence. When accordingly used, it can be:

- Preserve flatness- gain

- Reduce component temperature effects

- Enhance DC and RF stability

- Reduce distortion [13].

In general, shunt feedback can simply maintain stability at lower RF frequencies but weaken it at the higher frequencies [14].Series feedback is not favored for RF applications because it can decrease stability with respect to shunt feedback.Even though the compensated matching network amplifier enhances the other indicators by sacrificing the noise figure marginally, however by comparison, this structure is the excellent method with the best effect. So, compensated matching network amplifier is adopted and used in this work. 


\section{CIRCUIT ANALYSIS AND DESIGN STEPS}

In this section, the design analysis of LNA for $3 \mathrm{G} / 4 \mathrm{G}$ applications is presented. Table 1 shows the proposed low noise amplifier specifications. The proposed broadband class-A LNA circuit [6] with the compensated matching network with an NPN SIGE RF transistor BFU-730F device is shown in Figure 2. In this case, stable broadband gain and good impedance match simultaneously in the RF range, the compensated matching network amplifier was used. The computer-based method [15] has been used for amplifier designing.

Table 1. LNA design parameters

\begin{tabular}{ccccccc}
\hline Parameter & Center Frequency $\left(f_{c}\right)$ & Sweep Bandwidth $(B W)$ & Gain & Noise Figure & Stability & Supply Voltage \\
\hline Value & $2 \mathrm{GHz}$ & $600 \mathrm{MHz}$ & $>16.5 \mathrm{~dB}$ & $<0.7 \mathrm{~dB}$ & Unconditional stable & $2.25 \mathrm{~V}$ \\
\hline
\end{tabular}

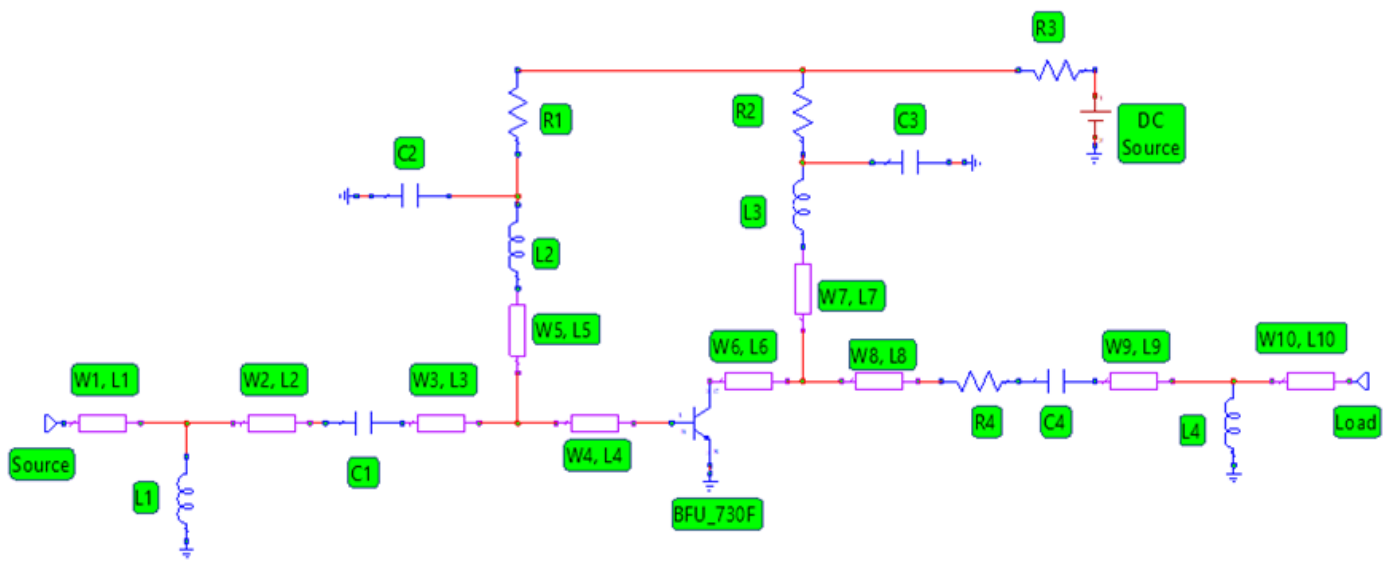

Figure 2. Proposed circuit schematic of broadband LNA

\subsection{Bias configuration}

Most microwave bipolar junction transistors (BJTs) are made via silicon in the NPN mode. Below $4 \mathrm{GHz}$, silicon BJT provides a reliable and low-cost solution to many electronics designs. The transistor dimensions are tiny to allow operations at microwave frequencies. The NPN SIGE RF transistor BFU-730F was used. This transistor has a small noise figure over the whole band along with enough gain at high frequency. From the datasheet, the BFU-730F amplifier provides less than $0.7 \mathrm{~dB}$ noise figure with a typical gain of $17.8 \mathrm{~dB}$ at $V_{C E}=2.025 \mathrm{~V}$ and $I c=5.8 \mathrm{~mA}$ operating point. A high DC current is necessary for high gain. Of course, the higher current generates higher noise. In order to obtain the greatest possible highfrequency gain, the noise figure is sacrificed to a certain extent.

\subsection{Stability analysis}

The stability of the amplifier is a very important consideration since, it is a measure of the resistivity of the system against the oscillation. For unconditional stability, the scattering parameters of the device determine the stability as shown in (1) to (4):

$$
\begin{aligned}
& \left|\Gamma_{\mathrm{S}}\right|<1 \\
& \left|\Gamma_{\mathrm{L}}\right|<1 \\
& \left|\Gamma_{\text {IN }}\right|=\left|\mathrm{S}_{11}+\frac{S 12 \times S 21 \times \Gamma L}{1-S 22 \times \Gamma L}\right|<1 \\
& \left|\Gamma_{\text {OUT }}\right|=\left|\mathrm{S}_{22}+\frac{S 12 \times S 21 \times \Gamma S}{1-S 11 \times \Gamma S}\right|<1
\end{aligned}
$$

where $\Gamma_{S}$ and $\Gamma_{L}$ are the source and load reflection coefficients, respectively. Moreover, the stability of the amplifier circuit was recognized by the stability factor $(k)$ as mentioned in (5). The state of unconditional stability can be realized from:

$$
\mathrm{K}=\frac{1-|S 11|^{2}-|S 22|^{2}+|\Delta|^{2}}{2|S 12 \times S 21|}>1
$$




$$
\Delta=\mathrm{S}_{11} \times \mathrm{S}_{22}-\mathrm{S}_{12} \times \mathrm{S}_{21}<1
$$

so, $\left|S_{11}\right|$ and $\left|S_{22}\right|$ must be less than 1 to achieve unconditional stability. In order to reach the entire frequency range, we have to use stabilizing branches since potential instabilities exist in the whole frequency band.

Table 2 shows the scattering parameters and stability factor $(\mathrm{K})$ to the Low noise transistor BFU $730 \mathrm{~F}$. The simulation has been done at the same biasing in our design $\left(\mathrm{V}_{\mathrm{CE}}=2.025 \mathrm{~V}, \mathrm{I}_{\mathrm{BB}}=19.1 \mu \mathrm{A}\right)$ as shown in Figure 3 Where it shows the circuit to obtain the scattering parameter of the RF BJT amplifier without any matching technique.

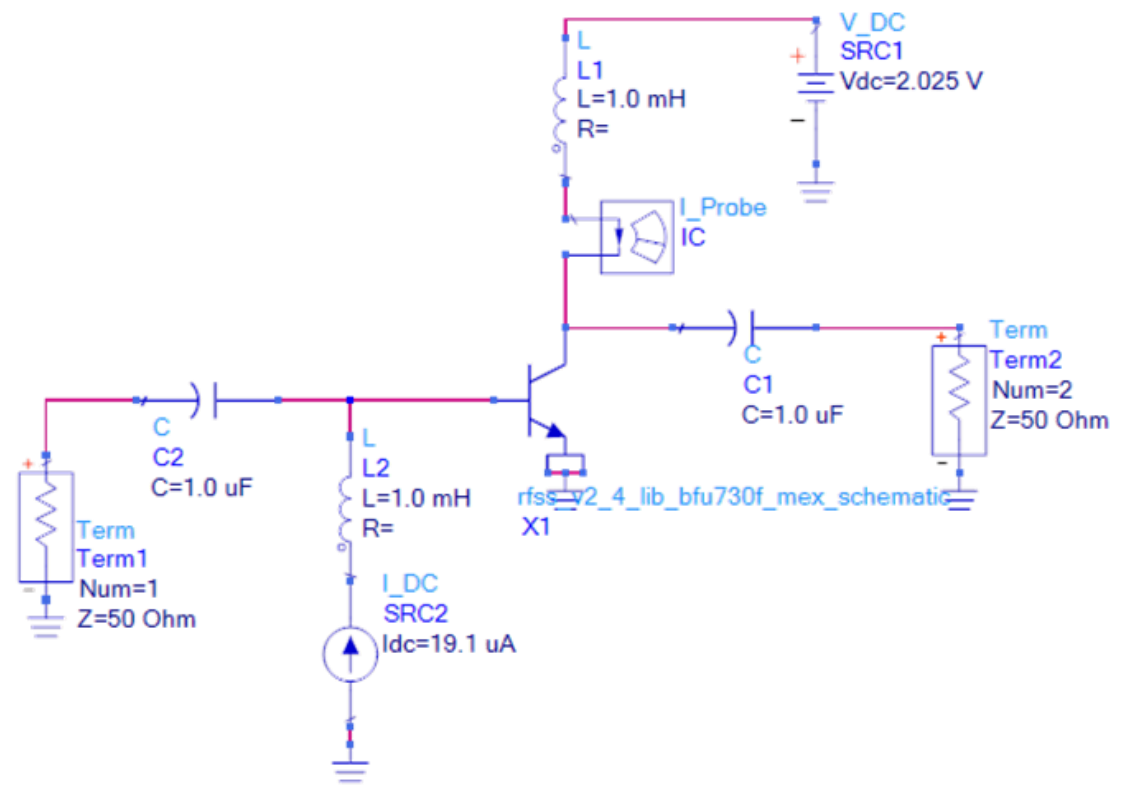

Figure 3. The circuit for S-parameters calculations of RF amplifier

Table 2. Scattering parameters and stability factor.

\begin{tabular}{cccccc}
\hline Center Freq. & $\mathrm{S}_{11}$ & $\mathrm{~S}_{12}$ & $\mathrm{~S}_{21}$ & $\mathrm{~S}_{22}$ & $\mathrm{~K}$ \\
\hline $2(\mathrm{GHZ})$ & $-4.2 \mathrm{~L}_{-106.16}$ & $-27.4 \mathrm{~L}_{41.6}$ & $14.5 \mathrm{~L}_{106.7}$ & $0.59 \mathrm{~L}_{-51.09}$ & 0.425 \\
\hline
\end{tabular}

At the outset, the circuit will achieve lower stability. A bias circuit is accommodated to make the stability factor as high as possible. The stability factor of BFU-730F in the static bias is determined as shown in Table 2. Therefore, the high stability factor and low noise characteristic amplifier the circuit is shown in Figure 2 is proposed. After simulation and optimization, a compensated matching network circuit is introduced in parallel to strengthen the stability.

\subsection{Broadband matching network design}

As shown in Figure 2, the biasing network is consisting of two bypass capacitors $\left(\mathrm{C}_{2}\right.$ and $\left.\mathrm{C}_{3}\right)$ to eliminate the power supply ripple. The two RF choke coils $\left(\mathrm{L}_{2}\right.$ and $\left.\mathrm{L}_{3}\right)$ prevent the RF signals while allow passing DC source voltage. Also, the quarter wavelength transmission line ( $\lambda \backslash 4$ T.L) keeps the design matching at the needed bandwidth; it makes the impedance high at RF signal, and preserves the impedance low at DC source voltage. There are three varieties of transmission lines (the two-wire, the coaxial and the microstrip transmission line).

The microstrip transmission line (MSTL) is the most proper for the construction of microwave amplifiers. The input network, which consists of capacitor $\mathrm{C} 1$, strikes a balance between the best noise figure and a fair input return loss as (DC block), microstrip line matched (Stepped impedance matching Technique)$\mathrm{T}$, shunt inductor L1 (equivalent for shunt single short stub to make so small size). The output matching network consists of a shunt resistor R4 (equivalent for transmission line matching) and shunt inductor L4 (equivalent for shunt single short stub) and capacitor C4 (DC blocking). The methodology mentioned in [16] has been used for matched element realization. The designed elements are shown in Table 3. 
Table 3. Transmission lines, and lumped components Values

\begin{tabular}{|c|c|c|c|c|c|c|c|c|c|}
\hline Symbols & $\mathrm{W}_{1}, \mathrm{~L}_{1}(\mathrm{~mm})$ & $\mathrm{W}_{2}, \mathrm{~L}_{2}(\mathrm{~mm})$ & $\mathrm{W}_{3}, \mathrm{~L}_{3}(\mathrm{~mm})$ & $\mathrm{W}_{4}, \mathrm{~L}_{4}(\mathrm{~mm})$ & $\mathrm{W}_{5}, \mathrm{~L}_{5}(\mathrm{~mm})$ & $\mathrm{W}_{6}, \mathrm{~L}_{6}(\mathrm{~mm})$ & $\mathrm{L}_{4}$ & $\mathrm{C}_{2}$ & $\mathrm{R}_{2}$ \\
\hline Values & $0.83,2.52$ & $0.55,1.11$ & $0.55,3.35$ & $0.55,3.14$ & $2.2 \mathrm{~V}$ & $70 \mathrm{~K} \Omega$ & $1 \mathrm{pF}$ & $0.5 \mathrm{pF}$ & \\
\hline Values & $10 \Omega$ & $20 \Omega$ & $20 \Omega$ & $7 \mathrm{nH}$ & $3.3 \mathrm{nH}$ & $8 \mathrm{nH}$ & $1 \mathrm{pF}$ & $2.4 \mathrm{pf}$ & \\
\hline
\end{tabular}

\subsection{LNA noise analysis}

Generally, in LNA noise circuit analysis, the input source is demonstrated as the parallel connection of an equivalent source admittance $Y_{S}$ and the noise current $\overline{i_{s}}$. The total noise donated by the two-port network is modeled as a noise voltage source $\overline{e_{n}}$ and a noise current source $\overline{i_{n}}$ as shown in Figure 4, assuming that the network is noiseless and linear.

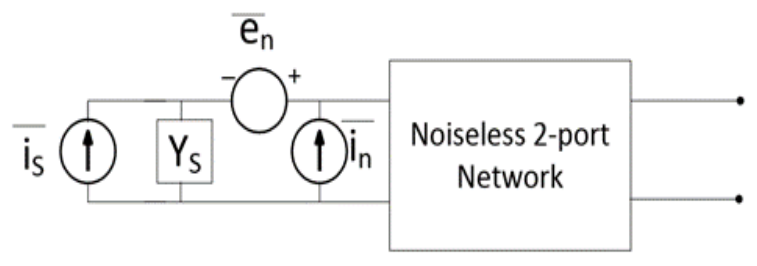

Figure 4. Equivalent noise model

The definition of noise figure is expressed as in (7):

$$
N F=\frac{\text { total output noise power }}{\text { output noise due to input source }}
$$

in an electronic circuit, there are several forms of noise sources, including thermal noise, shot noise, and flicker noise. However, thermal noise and shot noise are the most powerful types of noise in the LNA circuits. The Thermal noise increases with increasing Temperature and Resistance as in (8):

$$
v_{r m s}^{2}=4 k T R \Delta f
$$

where $K$ is Boltzmann constant, $R$ is equivalent resistance and $T$ is the temperature in kelvin. Additionally, shot noise occurs in microelectronic devices as a result of the inevitable spontaneous statistical variations in the electric current as charge carriers (such as electrons) traverse a junction. If electrons flow over a membrane, their arrival times are discrete. As stated previously, these discrete arrivals exhibit shot noise (9):

$$
i_{r m s}^{2}=2 q I \Delta f
$$

where $\left(i_{r m s}^{2}\right)$ is the current shot noise generator, $(q)$ is an electron charge elementary, $(\Delta f)$ is the the bandwidth in hertz at the considered noise is, and (I) is the DC following current.

\section{SIMULATION RESULTS}

The proposed LNA is designed according to a computer-based method. The scattering parameters are obtained by using the ADS [17] software for the NPN SIGE RF transistor BFU-730F device as shown in Figure 2. The designed elements values are given in Table 3. Where (W) is the transmission line Width and (L) is the transmission line length.

By notice, the manufacturer's passive element exhibits slightly different parasitical characteristics when optimised using the ADS method. The matching circuit for the input and the load network are both made of ideal microstrip transmission lines. For 3G/4G applications, the designed LNA proposed circuit has been simulated by using stepped impedance matching network technique and shunt short single stub technique to achieve high flatness gain of $(17.8 \mathrm{~dB})$. Figure 5 demonstrates the variation of the gain $\left(S_{21}\right)$ and the input return loss $\left(S_{11}\right)$ over the proposed bandwidth from $(1.7 \mathrm{GHz}$ to $2.3 \mathrm{GHz})$. 
As observed that the input return loss $\mathrm{S}_{11}$ varied between $(-7) \mathrm{dB}$ and (-11) $\mathrm{dB}$ and achieved a gain $S_{21}$ varied between $16.5 \mathrm{~dB}$ and $17.8 \mathrm{~dB}$. Thus, these values indicate a good matching and high gain over the interesting bandwidth. Also, Figure 6 shows the NF achieved a good result $(0.62 \mathrm{~dB}-0.69 \mathrm{~dB})$ over the LNA operating band $1.7 \mathrm{GHz}-2.3 \mathrm{GHz}$. This value indicates that the amount of noise added to the overall system is very low.

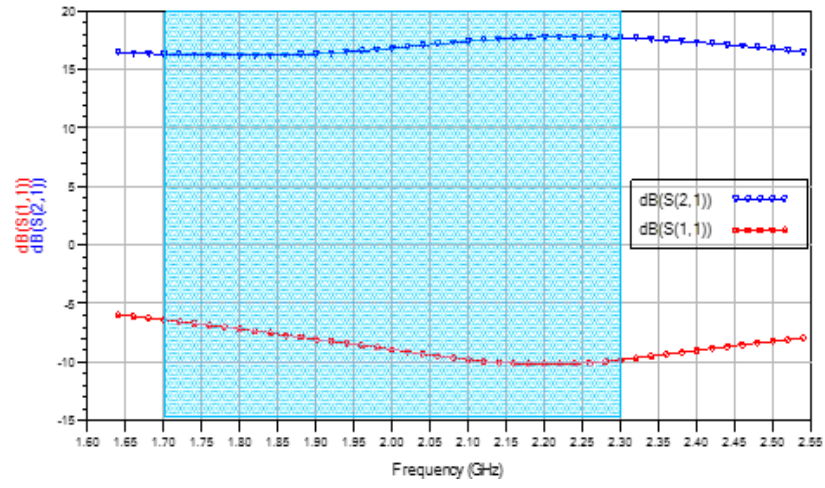

Figure 5. The gain_ $\left(S_{21}\right)$ and the input return loss $\left(S_{11}\right)$

From Figure 7, it can be observed that the stability factor $(K)$ is greater than 1 over the operating band. Thus, the conditions for unconditional stability are validated on the pass frequency band. Therefore, there is no risk to get oscillations.

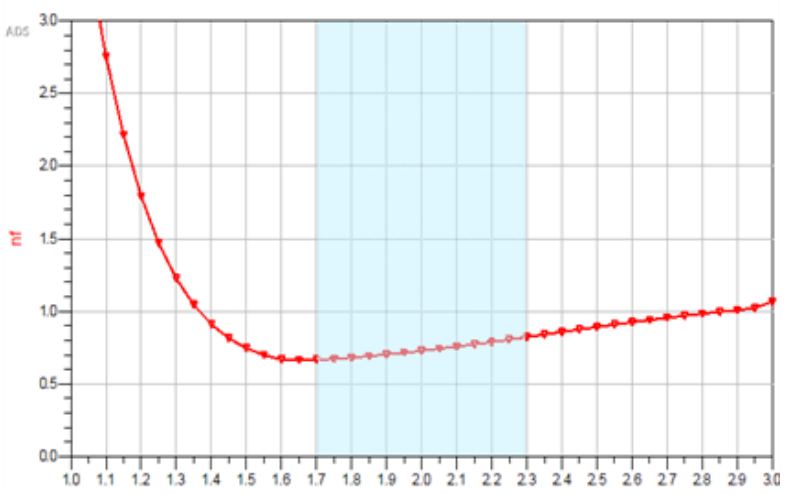

Figure 6. Plot of the noise figure versus frequency

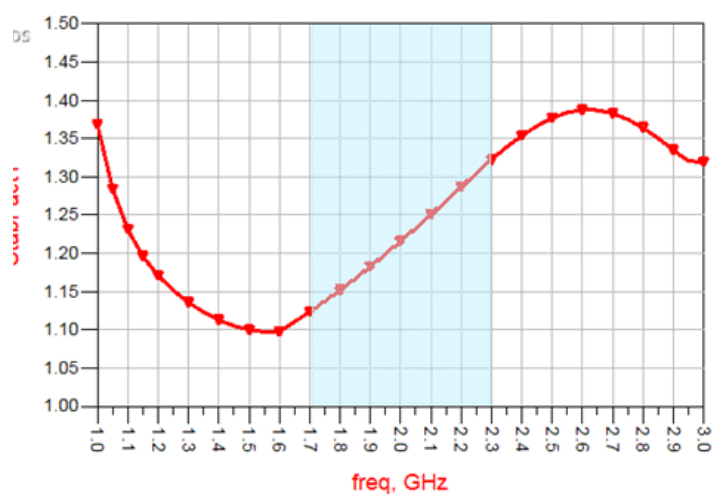

Figure 7. Plot of the stability factor $(\mathrm{K})$ versus frequency

\section{EXPERIMENTAL RESULTS}

Figure 8 shows the layout for the proposed LNA. Taking into account the peripheral's parasitic resistance, inductance, and capacitance in the box. The resistances of Murata's chip inductors, capacitors, and other companies' packages are sufficient in the simulation. The proposed broadband LNA is implemented using FR4 substrate material with a dielectric constant $\varepsilon_{r}=4.5$, thickness (h) of $1.6 \mathrm{~mm}$, and loss tangent $(\tan \delta=0.025)$. The printed circuit board is a one-layer configuration, it has an overall size of about $3 \times 2.6$ $\mathrm{cm}^{2}$ as shown in Figure 9.

The LNA measurements start with the quiescent current testing, then the S-parameters is measured using Vector Network Analyzer (VNA). The connections of the printed circuit board to the power supply and the network analyzer are shown in Figure 10. Figure 11 illustrates the values of the simulated gain $\left(S_{21}\right)$ which varied between $16.5 \mathrm{~dB}$ to $17.8 \mathrm{~dB}$ as well as the values of the simulated gain $\left(S_{21}\right)$ which varied between $16.5 \mathrm{~dB}$ to $17.8 \mathrm{~dB}$ over the proposed band $1.7 \mathrm{GHz}$ to $2.3 \mathrm{GHz}$ and the measured gain $\left(S_{21}\right)$ which varied between $15.5 \mathrm{~dB}$ to $17.1 \mathrm{~dB}$ over the proposed band $1.7 \mathrm{GHz}$ to $2.3 \mathrm{GHz}$. 


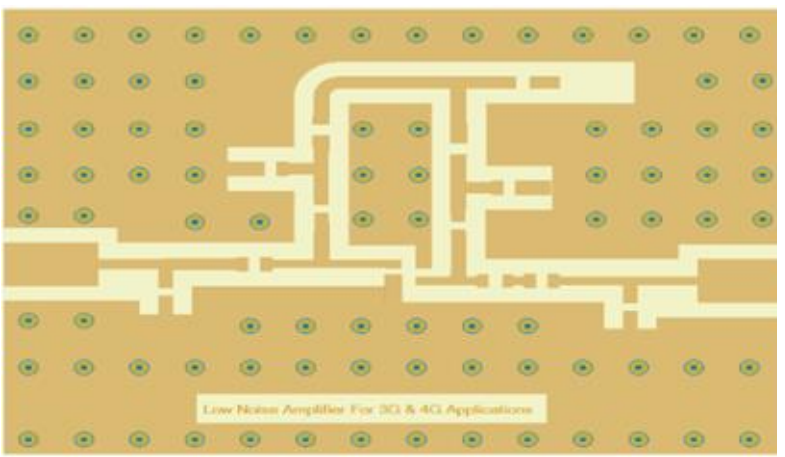

Figure 8. Layout of the proposed LNA

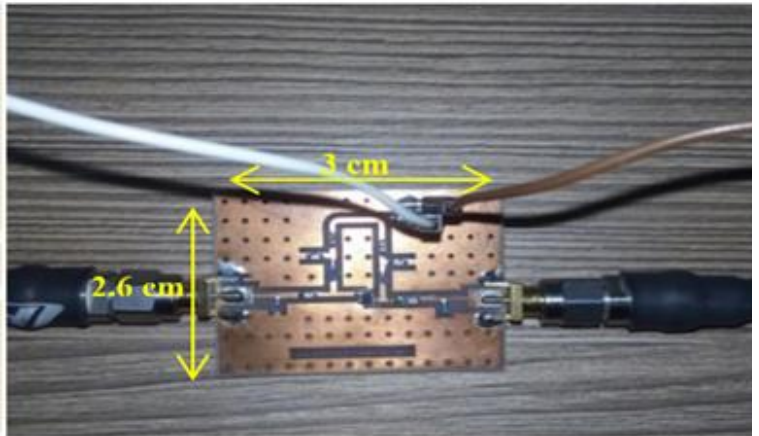

Figure 9. The PCB of the broadband LNA

The measurement shows that there is no difference between the values of simulated gain and measured gain at the center frequency $(2 \mathrm{GHz})$, but over the broadband, it almost less than $1 \mathrm{~dB}$. Any slight inequality between simulated and measured outcomes is due to the standard manufacture defects and the copper surface unevenness [18].

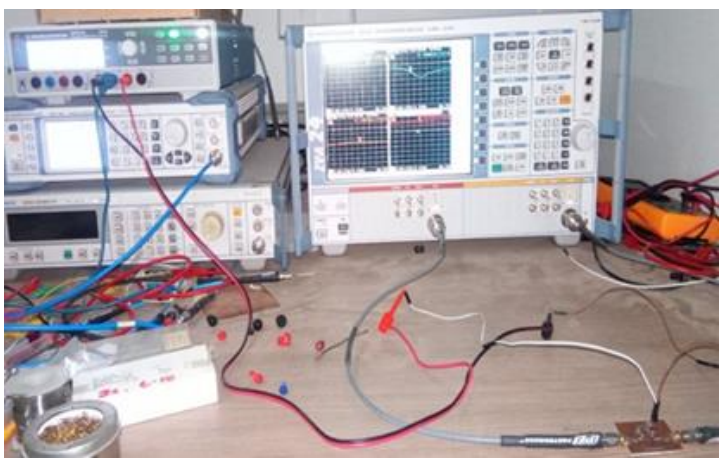

Figure 10. The measurements setup for the LNA circuit

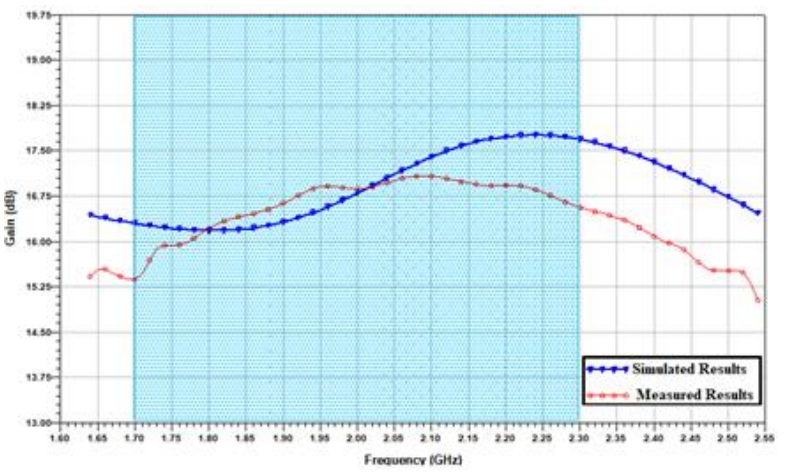

Figure 11. Measured and simulated results of the proposed LNA

Table 4 shows comparability between the suggested broadband LNA and other previously developed LNA circuits. The comparison shows that the suggested broadband LNA circuit achieved the lowest noise figure in addition to the leverage of the gain, small size, with relatively better return loss.

Table 4. Previous Work Comparison

\begin{tabular}{clllll}
\hline Ref. & \multicolumn{1}{c}{ Technology } & Frequency $(\mathrm{GHz})$ & $\mathrm{NF}(\mathrm{dB})$ & Gain $(\mathrm{dB})$ & Cost \\
\hline This Work & BFU-730F SIGE & $1.7-2.3$ & $0.62-0.69$ & $16.5-17.8$ & Low \\
{$[19]$} & SIGE Bipolar & 1.8 & 1.3 & 17 & High \\
{$[20]$} & AT-41410 Si-BJT & $1.75-2.15$ & N/A & $10-11.8$ & Moderated \\
{$[21]$} & ATF-54143 & 2.3 & 0.46 & 13.8 & Moderated \\
{$[22]$} & PHEMT ATF-54143 & 0.5 to 6 & 3.5 & 18 & Moderated \\
{$[23]$} & BFP720 & 2.3 & 1.15 & 34 & Moderated \\
{$[24]$} & SIGE HBT & $1.6-2.4$ & 1.5 & 18 & Moderated \\
{$[25]$} & SIGE HBT & $1-2$ & 1 & 13 & Moderated \\
\hline
\end{tabular}

\section{CONCLUSIONS}

With the assist of the Advanced Design System (ADS) and the compensated matching network and broadband matching theory, a LNA has been designed by steadily optimization and correcting the circuit parameters. The design was sufficed the electromagnetic (EM) simulation and the design result proved that the proposed broadband LNA has succeeded in a gain up $16.5 \mathrm{~dB}$, the flatness gain down $\pm 0.7 \mathrm{~dB}$, NF under $0.69 \mathrm{~dB}$. The circuit is designed and assembled on FR4 substrate material to reduce the LNA price where it can be extensively used in $(3 \mathrm{G} / 4 \mathrm{G})$ communication systems. The proposed circuit was implemented by using microstrip and the measured parameters are matched with the simulation results.

Design and implementation of a broad-band high gain low noise amplifier for ... (Ahmed M. Abdelmonem) 


\section{REFERENCES}

[1] A. Youssef, A. Ismail, and J. Haslett, "A Sub - 2 dB Noise Figure Wideband LNA in 65 nm CMOS for Mobile TV Applications," in 2010 Topical Meeting on Silicon Monolithic Integrated Circuits in RF Systems (SiRF), 2010, pp. 164-167, doi: 10.1109/SMIC.2010.5422982.

[2] D. Barras, F. Ellinger, and H. Jackel, "A Comparison between Ultra-Wideband and Narrow-Band Transceivers," TRLabs/IEEE Wireless, pp. 211-214, Jul 2002.

[3] Y. Lo and J. Kiang, "Design of Wideband LNAs using Parallel-to-Series Resonant Matching Network between Common Gate and Common Source Stages," in IEEE Transactions on Microwave Theory and Techniques, vol. 59, no. 9, pp. 2285-2294, Sept. 2011, doi: 10.1109/TMTT.2011.2160080.

[4] V. Doki, S. Nandanwar, and J. Thakkar, "Balanced Amplifier Technique for LNA in UHF Band," in 2015 Fifth Int. Conf. on Communication Systems and Network Technologies, 2015, pp. 24-27, doi: 10.1109/CSNT.2015.125.

[5] M M. Radmanesh, Advanced RF \& Microwave Circuit Design the Ultimate Guide to Superior Design. USA: AuthorHouse. 2018.

[6] G. Gonzales, "Microwave Transistor Amplifiers Analysis and Design," 2nd Edition, USA: Prentice Hall Upper, Saddle River New Jersey, 2007.

[7] M. Ben Amor, M. Loulou, S. Quintanel, and D. Pasquet, "A Dual Wideband CMOS LNA Design for the 4G of Wireless Applications," in 2008 3rd International Conference on Design and Technology of Integrated Systems in Nanoscale Era, 2008, pp. 1-4, doi: 10.1109/DTIS.2008.4540212.

[8] I. Biswas, A. J. Deka, and S. Bose, "Design of a $2.3 \mathrm{GHz}$ Low Noise Amplifier for WIMAX Applications," 2012 Int. Conf. on Devices, Circuits and Syst. (ICDCS), 2012, pp. 105-109, doi: 10.1109/ICDCSyst.2012.6188683.

[9] W-H. Hung, K-T. Lin, J-Y. Hsieh, and S-S. Lu, "A 2-6GHz Broadband CMOS Low-Noise Amplifier with Current Reuse Topology Utilizing a Noise-Shaping Technique," 2011 IEEE International Symposium of Circuits and Systems (ISCAS), 2011, pp. 1291-1294, doi: 10.1109/ISCAS.2011.5937807.

[10] M. Arsalan, D F. Amir, and T. Khan, "pHEMT LNA Design and Characterization for 4G Applications," 17th IEEE International Multi Topic Conference 2014, 2014, pp. 61-66, doi: 10.1109/INMIC.2014.7096912.

[11] Agilent Technologies Keysight, "Practical Noise-Figure Measurement and Analysis for Low-Noise Amplifier Designs," Application Note 1354, 2000. [Online]. Available: http://wwwtcad.stanford.edu/ goojs/RESEARCH/nf_lna.pdf

[12] R. Gilmore and L. Besser, "Practical RF Circuit Design for Modern Wireless Systems," vol. 2, Active Circuits and Systems, USA: Artech House, pp. 123-141, 2003.

[13] Peter B. Kenington, High-Linearity RF Amplifier Design, Norwood, MA: Artech House, 2000.

[14] C.-W. Kim, M.-S. Kang, P. T. Anh, H.-T. Kim, and S.-G. Lee, "An Ultra Wide-Band CMOS Low-Noise Amplifier for 3-5-GHz UWB System," in IEEE Journal of Solid-State Circuits, vol. 40, no. 2, pp. 544-547, Feb. 2005, doi: 10.1109/JSSC.2004.840951.

[15] S. M. Salah Eldeen, F A. Farag, and A. M. Moselhy, "CAD Tools Broadband Amplifier Design," in World Academy of Science Engineering and Technology International Journal of Electronics and Communication Engineering, vol. 5, no. 1, pp. 116-121, Jan 2011, doi: 10.5281/zenodo.1079356.

[16] J. Wang, S. He, F. You, W. Shi, J. Peng, and C. Li, "Codesign of High-Efficiency Power Amplifier and RingResonator Filter Based on a Series of Continuous Modes and Even-Odd-Mode Analysis," in IEEE Transactions on Microwave Theory and Techniques, vol. 66, no. 6, pp. 2867-2878, June 2018, doi: 10.1109/TMTT.2018.2819650.

[17] Keysight Technologies, "ADS 2019 Update 1.0 Product Release," Advanced Design System (ADS), 2019. [Online] Available: https://www.keysight.com/en/pd-2979469/ADS-2019-update-10?CC=EG\&IC=eng.

[18] X. Chen, "EM Modeling of Microstrip Conductor Losses Including Surface Roughness Effect," in IEEE Microwave and Wireless Components Letters, vol. 17, no. 2, pp. 94-96, Feb. 2007, doi: 10.1109/LMWC.2006.890326.

[19] O. Shana'a, I. Linscott, and L. Tyler, "Frequency-Scalable SiGe Bipolar RF Front- End Design," Proceedings of the IEEE 2000 Custom Integrated Circuits Conference (Cat. No.00CH37044), 2000, pp. 183-186, doi: 10.1109/CICC.2000.852645.

[20] A. Rachakh, E A. Larbi, Z. Jamal, A. Errkik, A. Tajmouati, and L. Mohamed, "A Novel Configuration of a Microstrip Microwave Wideband Power Amplifier for Wireless Application," TELKOMNIKA Telecommunication Computing Electronics and Control, vol. 16, no. 1, pp. 224-231, 2018, doi: 10.12928/telkomnika.v16i1.7369.

[21] A. Sidik, M Y. Fathany, and B R. Alam, "Design of Broadband Low Noise Amplifier (LNA) 4G LTE TDD 2.3 GHz for modem application," 2015 International Symposium on Intelligent Signal Processing and Communication Systems (ISPACS), 2015, pp. 488-492, doi: 10.1109/ISPACS.2015.7432821.

[22] T. Lianjuan and B. Jingfu, "An $0.5-6 \mathrm{GHz}$ ultra-wideband low noise amplifier design," 2011 International Conference on Electronics, Communications and Control (ICECC), 2011, pp. 2516-2519, doi: 10.1109/ICECC.2011.6066535.

[23] Tafriyana and B. R. Alam, "2.4 GHz Low Noise Amplifier Design for Broadband IoT Runway Application," 2019 International Symposium on Electronics and Smart Devices (ISESD), 2019, pp. 1-4, doi: 10.1109/ISESD.2019.8909450.

[24] J. Liu and B. N. Gao, "Design of 1.6-2.4 GHz Low Noise Amplifier Based on SiGe HBT," 2019 IEEE International Conference on Electron Devices and Solid-State Circuits (EDSSC), 2019, pp. 1-3, doi: 10.1109/EDSSC.2019.8754332.

[25] N. Deo, J. Wernehag, and J. Thelberg, "Low Power Highly Stable and Wideband LNA for GNSS Applications in SIGE technology," 2015 Nordic Circuits and Systems Conference (NORCAS): NORCHIP \& International Symposium on System-on-Chip (SoC), 2015, pp. 1-4, doi: 10.1109/NORCHIP.2015.7364395. 